\title{
BARROS, D. L. P. DE (ORG.) OS DISCURSOS DO DESCOBRIMENTO: 500 E MAIS ANOS DE DISCURSOS. SÃO PAULO: EDUSP; FAPESP, 2000, 270 PÁGS.
}

\author{
Resenhado por: Maria Aparecida R. Ottoni \\ e Maria Cecília de Lima
}

Esta obra constitui o primeiro volume da série Estante 500 anos, a qual é voltada para a 'discussão do Brasil', quinhentos anos após a chegada dos portugueses aqui, e é o resultado de um trabalho de busca de nossos sentidos e da contribuição de estudiosos do discurso e do texto para algumas possíveis interpretações de nossos 500 e ou mais anos de discursos. Nela, são apresentadas reflexões de pesquisadores(as) do discurso e do texto, a partir de perspectivas teóricas diversas, as quais diferem da do historiador ou da do sociólogo, ao tomar a sociedade e a História como discursos e textos que dialogam com outros e produzem sentidos. Assim, acredita-se que os trabalhos que compõem este volume podem contribuir para a reflexão conjunta sobre o Brasil, com o ponto de vista da linguagem e de seus sentidos.

O livro contém 16 (dezesseis) ensaios, de pesquisadores(as) brasileiros(as), nos quais são analisados temas importantes colhidos nesses cinco séculos de discursos de construção do imaginário nacional.

No primeiro ensaio, intitulado Ler a diferença, Edward Lopes examina a leitura da diferença e o olhar de estranhamento de europeus e de habitantes do Novo Mundo. Segundo o autor, na chegada dos europeus às terras brasileiras, houve um olhar de estranhamento por parte do observador que denota a sua incompetência em dar conta de transformar o seu “objeto de ver" (o índio) num “objeto do saber". Na relação europeu/ índio, este é visto como um ator de um espetáculo da diferença. Assim, o problema que se coloca para quem chega é o de ler essa diferença.

No segundo ensaio, Identidades e diferenças na construção dos espaços e atores do novo mundo, José L. Fiorin mostra que, na construção do espaço e dos atores do Novo Mundo, dois discursos se afrontam - o do paraíso/ 
homem natural e do inferno/homem degenerado - e contribuem para a construção da identidade nacional. Por meio da análise de $O$ Guarani, Fiorin destaca que os índios são ora tidos como valor positivo, ora como valor negativo. Às mulheres índias, a caracterização é outra, pois são exaltados os seus atributos sexuais.

No terceiro ensaio, de Eduardo P. Cañizal, Num lugar semântico do outro lado dos 500 anos, o autor analisa tramas ou figuras de linguagem que marcam os relatos do encontro entre ameríndios e europeus. Ele procura, de uma maneira clara e didática, desvendar os enigmas da significação presentes nas metáforas que compõem tanto as traduções quanto os originais dos textos de Caminha e de Colombo.

No quarto ensaio, A descoberta do Brasil pela Amazônia: o relato de viagem de Gaspar de Carvajal, Koch e outros analisam o relato de viagem de Gaspar de Carvajal, um dos mais importantes textos do conjunto de crônicas quinhentistas, que trata do descobrimento do rio Amazonas, mostrando a tensão existente entre o desejo do colonizador de dominar um novo discurso e a impossibilidade de fazê-lo. Nesse ensaio, os(as) autores(as) tentam caracterizar o gênero "crônica de viagem", e, em seguida, mostram o percurso discursivo de Carvajal. É importante salientar que, no momento em que diversos pesquisadores têm se voltado para a questão dos gêneros, quer seja textuais ou discursivos, os(as) autores(as) dão grande contribuição ao tentar caracterizar esse gênero.

O quinto ensaio, Quem é esse povo?, de Lúcia Teixeira, apresenta uma reflexão sobre a permanência entre nós, há mais ou menos quinhentos anos, de um confronto que põe de um lado o povo e de outro o que não é povo e, por oposição, costuma-se chamar elite. Para dar conta de um processo específico de produção de sentido para o Brasil, a autora toma como objetos concretos de diferentes sistemas semióticos textos diversos. Inegavelmente, a escolha da autora, no que diz respeito à análise de imagens, contribui para os estudos que têm procurado examinar as diferentes semioses, assim como os enriquece.

Nagamine Brandão, no sexto ensaio, Catequese e colonização no discurso jesuítico, objetiva apresentar uma leitura da leitura que o europeu fez do mundo ameríndio nos primeiros anos de contato. Ela faz um recorte que leva em conta o discurso dos primeiros missionários jesuítas no Brasil, 
restringindo-se especificamente a textos de Manoel da Nóbrega e José de Anchieta. Tais textos revelam-se ricos por espelharem não só o próprio envolvimento no trabalho missionário, mas também a mentalidade catequizadora do grupo a que pertenciam e, sobretudo, as implicações sociais e políticas de sua atuação no quadro geral da nossa incipiente História. O ensaio apresenta uma exposição clara e objetiva que facilita a leitura e compreensão pelos(as) leitores(as). Isso também pode ser percebido no próximo trabalho, de Eni Orlandi.

Neste, intitulado Entrar na sociedade geral dos cidadãos. Caminhos da História, trajetos do político, Orlandi compara o projeto para os índios de José Bonifácio de Andrada e Silva com os discursos dos missionários, mostrando que são produzidos a partir de lugares sociais diferentes e examinando a questão da cidadania. Dessa forma, ela mostra que o discurso de José Bonifácio, ao contrário do dos missionários, trata-se da formação de uma sociedade, da constituição do brasileiro como sujeito social, sujeito cidadão. Porém, como afirma a autora, isso não estava realmente constituído na República e nem o está hoje.

No oitavo ensaio, Esta é uma outra mesma história: os índios nos livros didáticos de história do Brasil, Diana L. P. de Barros discute se houve de fato mudança em relação ao trato do índio nos livros didáticos de História do Brasil. Ela analisa as imagens discursivas do índio nesses livros, revelando que, ainda hoje, ele não faz parte da História nesses discursos, mas, sim, é apresentado como marginal e o europeu como o homem civilizado de cujo ponto de vista hoje conhecemos a história do Brasil. A reflexão da autora sobre questões do ensino e dos discursos veiculados nos livros didáticos de História constitui-se em grande contribuição, pois, de certa forma, faz com que o(a) leitor(a) fique atento(a) para perceber que nem sempre a presença do índio nos livros didáticos implica o reconhecimento do mesmo como sujeito da História.

Beth Brait, com o objetivo de compor uma antologia comentada de algumas vozes de algumas pessoas que se posicionaram sobre a identidade lingüística nacional do Brasil, no nono ensaio, Em busca de uma identidade lingüística brasileira, comenta textos de cinco diferentes autores(as). Segundo a autora, as diferentes formas com que os(as) autores(as) abordam a questão da nacionalidade e da identidade lingüística brasileira têm a ver com o 
lugar que cada um ocupa em relação à língua e suas diferentes formas de existência e trato. Podemos dizer que a investigação de uma identidade lingüística brasileira se apresenta como bastante pertinente na pósmodernidade.

No décimo ensaio, Língua de civilização e línguas de cultura: a língua nacional do Brasil, Eduardo Guimarães, utilizando textos da Constituição do Brasil, busca refletir sobre a Língua Nacional do Brasil, destacando as línguas indígenas. Ele ressalta que mesmo tentando reconhecer as diversas línguas indígenas do Brasil, a língua nacional é a portuguesa, o que, de fato, silencia o índio brasileiro. Dessa forma, a diferença continua e os índios até hoje não existem no Brasil enquanto seres falantes.

Já Leonor L. Fávero, no ensaio A produção gramatical brasileira no século XIX - da gramática filosófica à gramática científica, examina a produção gramatical brasileira do século XIX. Segundo ela, a gramática é ao mesmo tempo o reflexo e o resultado de uma organização social e ferramenta da classe dominante. Assim, o gramático, mesmo sem perceber, desempenha o papel ideológico de exclusão do saber (e do poder) das camadas que não constituem a elite.

Quanto ao décimo segundo ensaio, Acontecimento e memória: discursos que (re)contam a história do Brasil-colônia, nele, Souza-e-Silva e Rocha refletem sobre o que podemos entender por "fato" e sobre a relação de tal "fato" com os discursos que a mídia produz a seu respeito. No debate que propõem, entrevêem uma não-coincidência entre fragmentos de discursos proferidos por ocasião da comemoração/manifestação de Ouro Preto (Inconfidência Mineira), os quais foram recuperados pela mídia, e os discursos produzidos pela mídia para "noticiar" o ocorrido, cumprindo sua "vocação informativa". A escolha desse objeto de estudo é interessante, visto que tem havido um crescente interesse de estudiosos pelo discurso veiculado pela mídia.

No décimo terceiro ensaio, $O$ discurso do outro e a identidade da mulher: da colonização à década de 1990, Izabel Magalhães discute, com evidências de quatro estudos sobre discurso e gênero, o que se diz sobre a mulher e o que a própria mulher diz de si, no contexto do debate sobre o discurso do outro, da diferença. O eixo central do ensaio é o estudo da relação do discurso tradicional de controle da mulher e um novo discurso de libera- 
ção e emancipação. Os quatro estudos sugerem que o discurso tradicional de controle sobre a mulher que se estabeleceu na Colônia é ainda forte no Brasil, em três dos contextos investigados. Por outro lado, tanto no contexto político, quanto de casais internacionais, em situações de contato com outras culturas, constatou-se uma transformação na prática discursiva. Enfim, essa pesquisa é de grande relevância por sua contribuição social, no que diz respeito às questões de gênero social e do papel da mulher na sociedade brasileira.

No décimo quarto ensaio, $A$ defesa da pátria: 1935 nos jornais e a memória discursiva da brasilidade, Bethania Mariani apresenta o confronto entre diferentes processos de produção de sentidos para a chamada Intentona Comunista. Ela discute qual o papel da imprensa ao produzir sentidos e servir de suporte à perpetuação de determinados acontecimentos caros à história oficial e de que modo os jornais retratam os sentidos antagônicos, derrota vs vitória, em situações de conflito político. Vale ressaltar que essa análise dos discursos em confronto é bastante pertinente para a formação/ construção do(a) leitor(a) crítico(a) e para mostrar a não-neutralidade da imprensa.

No ensaio A história em imagens da cidade, Kati E. Caetano, investiga as formas como o espaço urbano direciona o olhar público para figuras de seu passado, por meio do estudo de dois painéis e murais expostos em Curitiba. A autora busca decifrar os mecanismos de transformação presentes na passagem dos chamados 'eventos fundadores' para o relato e, desse relato, seja ele verbal ou visual, para a sua recursividade. A análise de textos imagéticos feita por Caetano contribui para a leitura de nossa história por meio de imagens, o que auxilia também na formação de leitores(as) de textos visuais.

No último dos ensaios desta obra, temos o texto de Sírio Possenti, Rindo do descobrimento do Brasil. Nele, o autor reflete sobre as poucas piadas a respeito do descobrimento do Brasil, ligando o raro tratamento humorístico à quase ausência de controvérsia em torno do tema. Sobre esse evento, como ele afirma, vivemos praticamente a situação do discurso único - na verdade, até menos do que isso: a situação de desconhecimento ou de desinteresse, e, assim, não pode mesmo ser controverso. Logo, não pode haver choques de discursos opostos e, dessa forma, explica-se que 
não haja piadas sobre o descobrimento. Para estudiosos do humor, esse pode ser um ponto a ser explorado.

Podemos ver, finalmente, que a diversidade de tipos de textos e abordagens teóricas presentes nesta obra constitui rica fonte de pesquisa para aqueles(as) que se interessam tanto pelas questões da linguagem quanto pelas questões dos 500 anos de descobrimento do Brasil. Assim, não é destinado só a lingüistas, mas a um público amplo.

\section{REFERÊNCIAS BIBLIOGRÁFICAS}

Alencar, J. de. O Guarani. São Paulo: Ática, 1995.

Carvajal, G. de. A relação do descobrimento do rio Amazonas. In: A. Porro. As crônicas do rio Amazonas: notas etno-históricas sobre as antigas populações indígenas da Amazônia. Petrópolis: Vozes, 1992.

Colombo, C. Diários da descoberta da América. Porto Alegre: L\&PM, 1998. Cortesão, J. A carta de Pero Vaz de Caminha. Rio de Janeiro: Edições Livros de Portugal Ltda., 1943. 